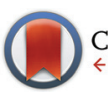

CrossMark $\leftarrow$ click for updates

Cite this: Dalton Trans., 2014, 43 14432

Received 4th April 2014

Accepted 23rd May 2014

DOI: $10.1039 / \mathrm{c} 4 \mathrm{dt} 01008 \mathrm{f}$

www.rsc.org/dalton

\section{Heterocyclic substituted methanides as promising alternatives to the ubiquitous nacnac ligand $\uparrow$ t}

\author{
David-R. Dauer and Dietmar Stalke*
}

A series of group 13 complexes containing deprotonated bisheterocyclomethanes have been prepared and structurally as well as spectroscopically characterised. In the case of the parent neutral homo-disubstituted bisheterocyclomethanes bis-(benzoxazol-2-yl)-methane (abbreviated as $\left.\left(\mathrm{NCOC}_{6} \mathrm{H}_{4}\right)_{2} \mathrm{CH}_{2}\right)$ (1) and bis-(benzothiazol-2-yl)-methane (abbreviated as $\left.\left(\mathrm{NCSC}_{6} \mathrm{H}_{4}\right)_{2} \mathrm{CH}_{2}\right)(\mathbf{2})$, two interesting ligand systems were investigated with respect to their coordination abilities toward group 13 metals. Upon deprotonation of the acidic methylene bridge in each case a $\beta$-diketiminate-like structure is formed, where the negative charge becomes delocalised about the whole ligand framework. There is a mesomeric stabilisation between the carbanionic and the amidic resonance structure. The ligands mentioned above were treated with $\mathrm{AlMe}_{3}$, $\mathrm{AlMe}_{2} \mathrm{Cl}$ and $\mathrm{GaMe}_{3}$ to achieve deprotonation of the backbone and coincidental metal complexation. The resulting complexes $\left[\mathrm{Me}_{2} \mathrm{Al}\left\{\left(\mathrm{NCOC} \mathrm{H}_{4}\right)_{2} \mathrm{CH}\right\}\right](3),\left[\mathrm{Me}_{2} \mathrm{Al}\left\{\left(\mathrm{NCSC}_{6} \mathrm{H}_{4}\right)_{2} \mathrm{CH}\right\}\right]$ (4), [CIMeAl$\left.\left\{\left(\mathrm{NCOC}{ }_{6} \mathrm{H}_{4}\right)_{2} \mathrm{CH}\right\}\right]$ (5), [CIMeAl\{ $\left.\left.\left(\mathrm{NCSC}_{6} \mathrm{H}_{4}\right)_{2} \mathrm{CH}\right\}\right](6),\left[\mathrm{Me}_{2} \mathrm{Ga}\left\{\left(\mathrm{NCOC}_{6} \mathrm{H}_{4}\right)_{2} \mathrm{CH}\right\}\right]$ (7), and $\left[\mathrm{Me}_{2} \mathrm{Ga}\left\{\left(\mathrm{NCSC}_{6} \mathrm{H}_{4}\right)_{2} \mathrm{CH}\right\}\right]$ (8) were structurally characterized in the solid state by $\mathrm{X}$-ray single crystal diffraction and in solution by different (heteronuclear) 1D/2D-NMR spectroscopic techniques. Each of those molecules shows a nearly planar arrangement with the group 13 metal cation coordinated by the two ring nitrogen atoms of the conjugated heterocycles. Furthermore, in this work $\left(\mathrm{NCOC}_{6} \mathrm{H}_{4}\right)_{3} \mathrm{C}\left(\mathrm{C}_{3} \mathrm{H}_{7}\right)(9)$ could be isolated, which might turn out to be a promising analogue of the omnipresent trisoxazoline ligands in asymmetric catalysis.

\section{Introduction}

Referring to the monoanionic $\beta$-diketiminate ligand, the socalled nacnac ligand, enabling stabilisation of the main group elements in the low oxidation state, new ligand systems should be exploited mimicking those electronic and steric properties. In the case of nacnac substituted systems it is known that the scaffold tends to deviate from a planar arrangement within metal coordination by means of twisting or bending, and merely the backbone remains in plane. This deviation is caused by the flexible but bulky organic substituents at the imine moieties. Although this feature of the twisting seems to be problematic, it also offers an efficient shielding of the coordinated (low-valent) metal cations, which are sensitive towards reactions with electrophiles or dimerization. ${ }^{1}$

Institut für Anorganische Chemie der Georg-August-Universität Göttingen,

Tammannstr. 4, 37077 Göttingen, Germany.

E-mail: dstalke@chemie.uni-goettingen.de; Fax: +4955139 33373;

Tel: +495513933000

$\dagger$ Dedicated to Professor Frank T. Edelmann on the occasion of his $60^{\text {th }}$ birthday. \$Electronic supplementary information (ESI) available: Tables of data collection parameters, bond lengths and angles for compounds 1-9, 2D-NMR spectra of 3, $\mathbf{4}$ and $\mathbf{8}$, additional crystal structures of $\mathbf{4 , 5}$ and 7, nine X-ray files in CIF format. CCDC 995110-995118. For ESI and crystallographic data in CIF or other electronic format see DOI: 10.1039/c4dt01008f
Therefore, the new designed ligand systems shown in Scheme 1 should maintain more rigidity and lead to a more planar alignment in the corresponding metal complexes. Due to this planarity within the six-membered metalla heterocycle $\mathrm{C}_{3} \mathrm{~N}_{2} \mathrm{M}$ the orbital overlap between the donor atoms and the chelated metal atom should be increased, so that a more efficient conjugation and hence delocalisation can be obtained.

In former publications, we also investigated related compounds containing pyridyl substituents instead of benzoxazole and benzothiazole. ${ }^{2}$ Several complexes of this bis-(pyrid-2-yl)-methanide with group 1 and 13 metals could be synthesised and structurally characterized by X-ray diffraction: representing the group 1 complexes [([12]crown- 4$\left.)_{2} \mathrm{Li}\right]-$ $\left[\mathrm{Li}\left\{\left(2-\mathrm{NC}_{5} \mathrm{H}_{4}\right)_{2} \mathrm{CH}\right\}\right]$ can be highlighted as a solvent separated ion pair or $\left[(\text { thf })_{2} \mathrm{Li}\left\{\left(2-\mathrm{NC}_{5} \mathrm{H}_{4}\right)_{2} \mathrm{CH}\right\}\right]$ as a monomeric lithiated compound both solely yielding $\mathrm{Li}-\mathrm{N}$ contacts. ${ }^{3,4}$ Additionally, some group 13 complexes like $\left[\mathrm{Me}_{2} \mathrm{Al}\left\{\left(2-\mathrm{NC}_{5} \mathrm{H}_{4}\right)_{2} \mathrm{CH}\right\}\right]$ and

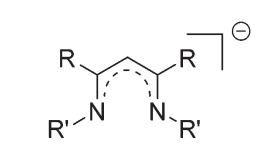

$\mathrm{R}=$ alkyl; $\mathrm{R}^{\prime}$ = alkyl, aryl

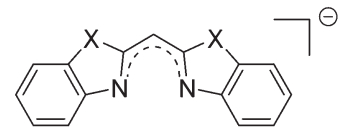

$x=0, s$
Scheme 1 Similarities between the nacnac ligand (left) and the bisheterocyclomethanides (right). 
$\left[\mathrm{Me}_{2} \mathrm{Ga}\left\{\left(2-\mathrm{NC}_{5} \mathrm{H}_{4}\right)_{2} \mathrm{CH}\right\}\right]$, where formally the (thf $)_{2} \mathrm{Li}$ unit is replaced by a $\mathrm{Me}_{2} \mathrm{Al}$ or $\mathrm{Me}_{2} \mathrm{Ga}$ moiety, were prepared., ${ }^{5,6}$ Moreover, this kind of ligand system was varied by replacing the bridging $\mathrm{CH}$ unit isoelectronically by $\mathrm{N}^{7,8} \mathrm{P}^{9,10}$ or As. ${ }^{11,12}$ The corresponding main group metal complexes were investigated.

In the past decade many main group metal containing $\beta$-diketiminate structures were synthesised and fully characterized. ${ }^{13-25}$ The presented aluminium(III) and gallium(III) complexes 3-8, which are described in the following, can be compared with many analogue compounds of the Dipp-substituted nacnac ligand. These complexes embrace aluminium(III), gallium(III) and indium(III) compounds and, in the case of $\mathrm{Al}$ and $\mathrm{Ga}$, also the reduced species in the oxidation state $+\mathrm{I}^{26-28}$ The former range from the alkyl over the hydride to halide substituted metal centres. The latter, the so-called metallylenes, are rarely known and offer interesting prospects as ligands in catalysis, where they might replace $\mathrm{N}$-heterocyclic carbenes or phosphanes. ${ }^{29,30}$ Furthermore the dialkylaluminium $\beta$-diketiminates show catalytic activities towards ring-opening polymerisation. ${ }^{31}$

The bisheterocyclomethanides show three optional donor sites: the deprotonated bridging carbanionic center, the ringchalcogene (oxygen or sulfur) and -nitrogen atoms. Because $\mathrm{O}$ and $\mathrm{S}$ do not share the same good Lewis-donor abilities of the ring-nitrogen atoms, each of the metallated species shows a nacnac-like coordination, wherein the metal gets chelated by the two heteroaromatic nitrogen atom donors. It should be noted that the presented ligand systems show also analogy to the popular bis-(oxazolin-2-yl)-methanes, which are used in asymmetric catalysis. In contrast to $\mathbf{1}$ and $\mathbf{2}$ those ligands consist of saturated not benzannulated heterocycles with chiral centres, which can transfer chiral information in catalysis. ${ }^{32}$

\section{Results and discussion}

\section{Syntheses}

The herein discussed bisheterocyclomethanes 1 and 2 mimic the related $\beta$-diketiminate ligand. Therefore, formally the imine substituent in the case of nacnac is fixed to the backbone of the ligand by building up an additional five-membered heterocycle containing either oxygen or sulfur atoms as additional donor sites.

As depicted in Scheme 2 both ligand systems were synthesised in a cyclocondensation reaction of a suitable linker

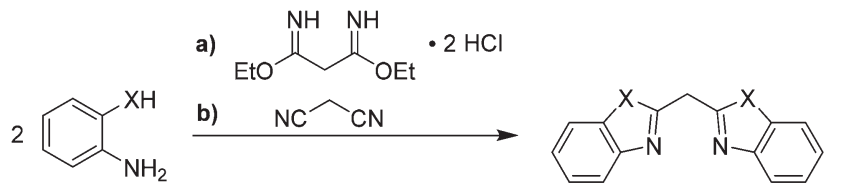

a) $X=O(1)$

b) $X=S(2)$

Scheme 2 Cyclocondensation reactions for synthesis of the parent ligand systems 1 and 2.

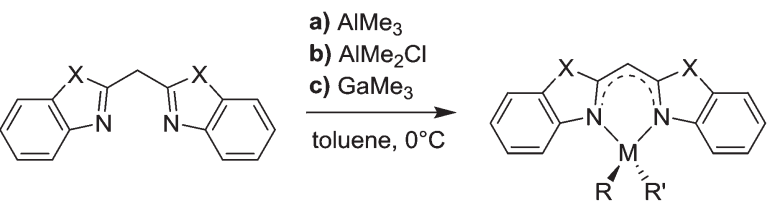

a) $M R R^{\prime}=A I M e_{2}, \quad X=O(3), S(4)$

b) $M R R^{\prime}=A I M e C l, X=O(5), S(6)$

c) $M R R^{\prime}=\mathrm{GaMe}_{2}, \quad X=O(7), \mathrm{S}(8)$

Scheme 3 Syntheses of the metallated compounds 3-8.

derived from malonic acid and two equivalents of the corresponding ortho-substituted anilines.

The reaction pathway (a) in Scheme 2 shows that the cyclocondensation reaction of the phenol derivative is more complicated as in the case of the thiophenol (b). Therefore, the former malononitrile has to be further activated before it undergoes a reaction with the phenolic nucleophile. This can be achieved by generating the derived ethylbisimidate dihydrochloride, wherein ammonia as well as ethanol act as leaving groups. $^{33}$

The syntheses of the closely related $\left[\mathrm{Me}_{2} \mathrm{Al}\left\{\mathrm{Dipp}_{2}\right.\right.$ nacnac $\left.\}\right]$ and $\left[\mathrm{Me}_{2} \mathrm{Ga}\left\{\right.\right.$ Dipp $_{2}$ nacnac $\left.\}\right]$ can be achieved by a facile reaction of nacnacH with $\mathrm{AlMe}_{3}$ and $\mathrm{GaMe}_{3}$, respectively. ${ }^{13,14,31}$ Referring to this also LH 1 and 2 can be deprotonated at the acidic methylene bridge by release of methane and coordinated by the group 13 metal in a concerted way (Scheme 3). In this reaction protocol many different metallated compounds are accessible and can be compared structurally.

In this context the effect of the diverging metal coordination $(\mathrm{M}=\mathrm{Al}, \mathrm{Ga})$ and moreover the related substituents at these metal cations $\left(\mathrm{R}=\mathrm{R}^{\prime}=\mathrm{Me} ; \mathrm{R}=\mathrm{Me}, \mathrm{R}^{\prime}=\mathrm{Cl}\right)$ on the bonding situation within the different ligand systems should be investigated.

\section{Structural data}

In the following part a structural comparison of compounds 1-8, which could be obtained by the earlier mentioned reaction protocols, will be discussed. For a better commensurability also the molecular solid state structures of the parent ligand systems 1 and 2 have been determined by X-ray single crystal diffraction and are shown in Fig. 1 and 2 .

Exemplarily for the metallated species the crystal structures of 3, 6 and 8 are depicted in the anisotropic displacement parameter plots in Fig. 3-5. Selected (averaged) bond lengths and angles are listed in Table 1 . The metallated species 3-8 have several intrinsic features in common, which have to be highlighted:

(a) In comparison with the deprotonated conjugated ligand system it is obvious that the free ligand LH shows in both cases a considerably larger torsion angle concerning the $\mathrm{C}-\mathrm{N}$ bonds within the heterocycles.

(b) Upon deprotonation the whole ligand system becomes nearly planar in each molecule and the metal cations are coordinated exclusively by the two ring-nitrogen donor atoms. 


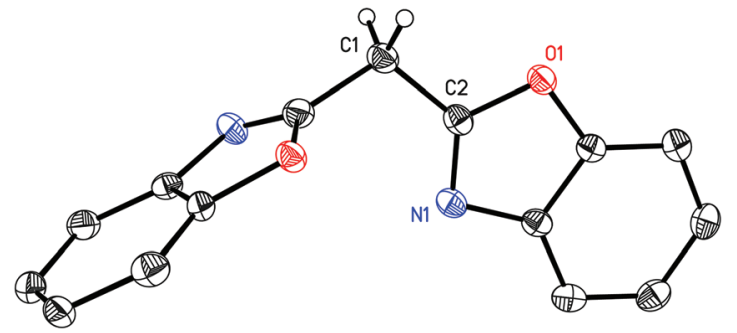

Fig. 1 Molecular structure of $\left(\mathrm{NCOC}_{6} \mathrm{H}_{4}\right)_{2} \mathrm{CH}_{2}$ (1). Anisotropic displacement parameters are depicted at the $50 \%$ probability level. Hydrogen atoms are omitted for clarity except the methylene bridge. Structural data are given in Tables 1 and 2.

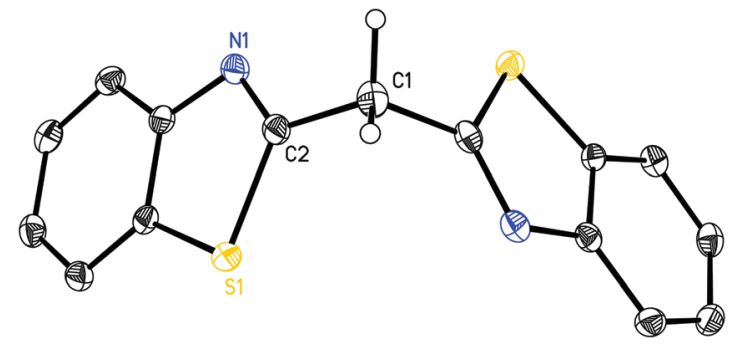

Fig. 2 Molecular structure of $\left(\mathrm{NCSC}_{6} \mathrm{H}_{4}\right)_{2} \mathrm{CH}_{2}$ (2). Anisotropic displacement parameters are depicted at the $50 \%$ probability level. Hydrogen atoms are omitted for clarity except the methylene bridge. Structural data are given in Tables 1 and 2 .

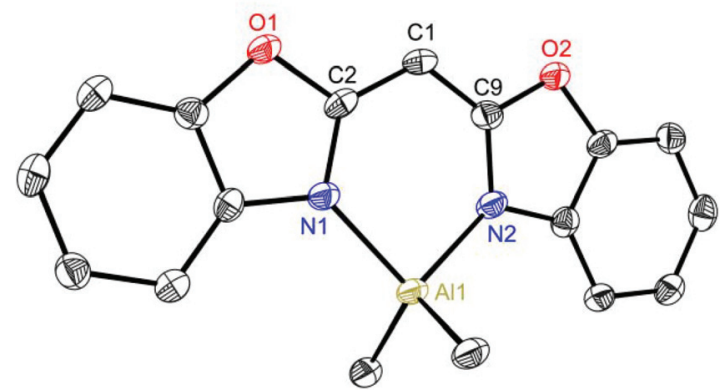

Fig. 3 Molecular structure of $\left[\mathrm{Me}_{2} \mathrm{Al}\left\{\left(\mathrm{NCOC}_{6} \mathrm{H}_{4}\right)_{2} \mathrm{CH}\right\}\right]$ (3). Anisotropic displacement parameters are depicted at the $50 \%$ probability level. Hydrogen atoms are omitted for clarity. Structural data are given in Tables 1 and 2.

(c) Furthermore, the metals are significantly dislocated from the ideal $\mathrm{C}_{3} \mathrm{~N}_{2}$ planes, ranging from 10.93(27) to 29.57 (26) pm, depending on the heteroatom in the backbone of the ligand.

(d) The experimentally determined $\mathrm{C}-\mathrm{C}$ and $\mathrm{C}-\mathrm{N}$ distances for 3-8 span the narrow range of 1.380(3) to 1.394(9) $\AA$ and 1.323(9) to $1.365(3) \AA$, respectively. These facts are an indicator of an apparent fully conjugated and delocalised ligand character, as far as the abovementioned bonds are concerned.

(e) The observed $\mathrm{N}-\mathrm{M}-\mathrm{N}$ bite angle inside the formed $\mathrm{C}_{3} \mathrm{~N}_{2} \mathrm{M}$ metalla heterocycle is the narrowest one (89.2(2)-96.84 $\left.(9)^{\circ}\right)$ whereas all the other angles are wider than $120^{\circ}$.

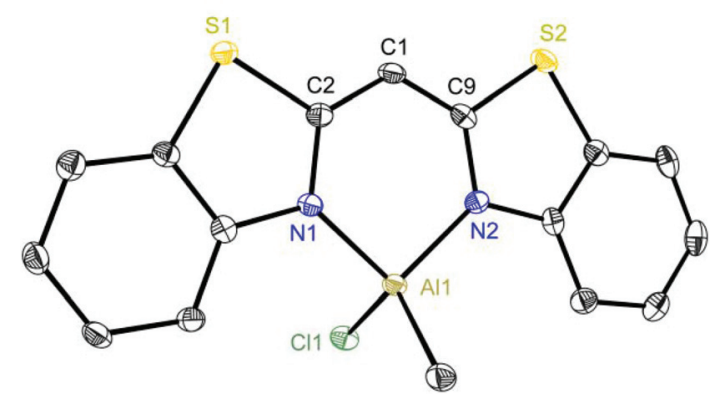

Fig. 4 Molecular structure of [CIMeAI $\left.\left\{\left(\mathrm{NCSC}_{6} \mathrm{H}_{4}\right)_{2} \mathrm{CH}\right\}\right]$ (6). Anisotropic displacement parameters are depicted at the $50 \%$ probability level. Hydrogen atoms and the positional disorder are omitted for clarity. Structural data are given in Tables 1 and 2.

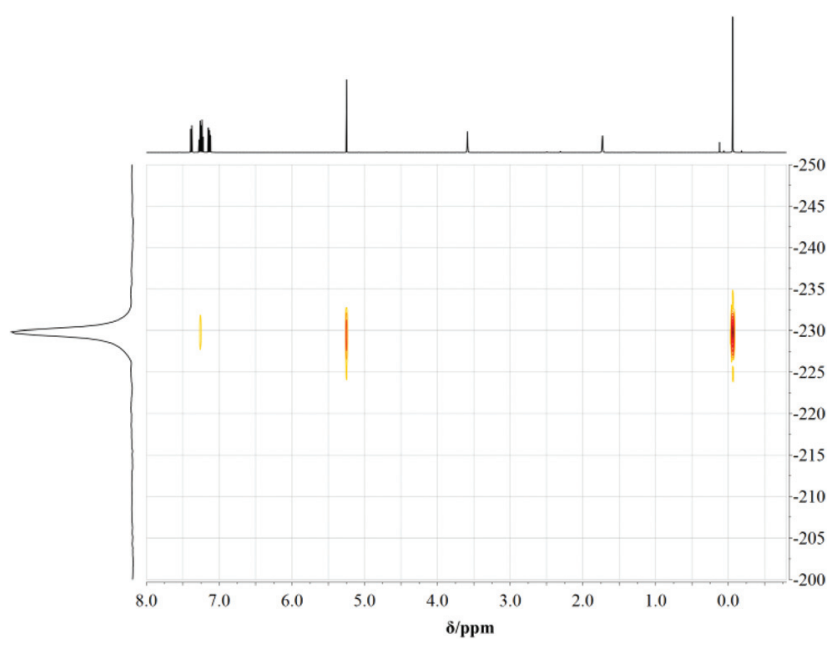

Fig. $5{ }^{1} \mathrm{H},{ }^{15} \mathrm{~N}-\mathrm{HMBC}-\mathrm{NMR}$ spectrum of 7 .

Table 1 Selected bond lengths (Å) and angles $\left(^{\circ}\right)$ for compounds 1-8

\begin{tabular}{|c|c|c|c|c|}
\hline & 1 & 2 & 3 & 4 \\
\hline $\mathrm{M}-\mathrm{N}(\mathrm{av})$ & - & - & $1.9176(20)$ & $1.9233(14)$ \\
\hline$C_{i p}-\mathrm{C}_{\mathrm{br}}$ (av) & 1.4891(15) & $1.5106(15)$ & $1.380(3)$ & $1.390(2)$ \\
\hline $\mathrm{N}-C_{i p}(\mathrm{av})$ & $1.2864(14)$ & $1.2955(16)$ & $1.346(3)$ & $1.3518(19)$ \\
\hline $\mathrm{N}-\mathrm{M}-\mathrm{N}$ & - & - & $91.67(9)$ & $94.79(6)$ \\
\hline \multirow[t]{2}{*}{$C_{i p}-\mathrm{C}_{\mathrm{br}}-C_{i p}$} & $111.23(9)$ & $109.59(14)$ & $119.5(2)$ & $123.54(14)$ \\
\hline & 5 & 6 & 7 & 8 \\
\hline $\mathrm{M}-\mathrm{N}(\mathrm{av})$ & $1.8930(17)$ & $1.894(2)$ & $1.996(6)$ & $1.9945(13)$ \\
\hline$C_{i p}-\mathrm{C}_{\mathrm{br}}(\mathrm{av})$ & $1.382(2)$ & $1.388(3)$ & $1.394(9)$ & $1.3909(19)$ \\
\hline $\mathrm{N}-C_{i p}(\mathrm{av})$ & $1.348(3)$ & $1.365(3)$ & $1.323(9)$ & $1.3436(19)$ \\
\hline $\mathrm{N}-\mathrm{M}-\mathrm{N}$ & 94.33(11) & $96.84(9)$ & $89.2(2)$ & 92.99(8) \\
\hline$C_{i p}-\mathrm{C}_{\mathrm{br}}-C_{i p}$ & $120.2(3)$ & $124.1(2)$ & $119.7(6)$ & $124.0(2)$ \\
\hline
\end{tabular}

br = bridge; $i p=i p s o$.

The most interesting feature within the series of the obtained structures is the deviation of the metal atom from the extended plane, which is made from the $\mathrm{N} 1-\mathrm{C} 2-\mathrm{C} 1-\mathrm{C} 9-\mathrm{N} 2$ 
Table 2 Folding parameters for $1-8$

\begin{tabular}{llll}
\hline Compound & $\begin{array}{l}\text { Metal dist. from } \\
\mathrm{C}_{3} \mathrm{~N}_{2} \text { plane }(\mathrm{pm})\end{array}$ & $\begin{array}{l}\text { Torsion } \\
\text { angle }\left(^{\circ}\right)\end{array}$ & $\begin{array}{l}\text { Folding } \\
\text { angle (o) }\end{array}$ \\
\hline$\left(\mathrm{NCOC}_{6} \mathrm{H}_{4}\right)_{2} \mathrm{CH}_{2}(\mathbf{1})$ & - & $81.3(9)$ & - \\
$\left(\mathrm{NCSC}_{6} \mathrm{H}_{4}\right)_{2} \mathrm{CH}_{2}(2)$ & - & $188.98(24)$ & - \\
{$\left[\mathrm{Me}_{2} \mathrm{Al}\left\{\left(\mathrm{NCOC}_{6} \mathrm{H}_{4}\right)_{2} \mathrm{CH}\right\}\right](3)$} & $29.57(26)$ & $1.0(8)$ & $9.12(8)$ \\
{$\left[\mathrm{Me}_{2} \mathrm{Al}\left\{\left(\mathrm{NCSC}_{6} \mathrm{H}_{4}\right)_{2} \mathrm{CH}\right\}\right](\mathbf{4})$} & $13.79(29)$ & $1.2(6)$ & $1.36(2)$ \\
{$\left[\mathrm{ClMeAl}\left\{\left(\mathrm{NCOC}_{6} \mathrm{H}_{4}\right)_{2} \mathrm{CH}\right\}\right](5)$} & $18.06(32)$ & - & $3.69(40)$ \\
{$\left[\mathrm{ClMeAl}\left\{\left(\mathrm{NCSC}_{6} \mathrm{H}_{4}\right)_{2} \mathrm{CH}\right\}\right](\mathbf{6})$} & $10.93(27)$ & $0.6(8)$ & $1.21(2)$ \\
{$\left[\mathrm{Me}_{2} \mathrm{Ga}\left\{\left(\mathrm{NCOC}_{6} \mathrm{H}_{4}\right)_{2} \mathrm{CH}\right\}\right](7)$} & $14.34(3)$ & - & $3.62(2)$ \\
{$\left[\mathrm{Me}_{2} \mathrm{Ga}\left\{\left(\mathrm{NCSC}_{6} \mathrm{H}_{4}\right)_{2} \mathrm{CH}\right\}\right](8)$} & $20.61(26)$ & - & $8.90(6)$
\end{tabular}

array. With this $\mathbf{M} \cdots$ plane distance the folding angle between both heteroaromatic substituents is associated, which can be seen as a reason for the different deviations. Various data concerning the M...plane distances, the torsion and the folding angles are listed in Table 2.

To highlight this special aspect the molecular structures of 3 and 8 are shown in Fig. 3 and 6. Both species exhibit the greatest metal distance from the $\mathrm{C}_{3} \mathrm{~N}_{2}$ plane $(29.57(26)$ and $20.61(26)^{\circ}$, respectively) and also the greatest folding angle of the heteroaromates $\left(9.12(8)\right.$ and $8.90(6)^{\circ}$, respectively). As a representative of the $\mathrm{AlMeCl}$ containing species the molecular structure of 6 is shown in Fig. 4.

Concerning the series of the synthesised group 13 metal complexes of the bis-(benzothiazol-2-yl)- and bis-(benzoxazol2-yl)-methanides, one has to emphasize that in the case of the oxygen containing ligand on average the bite angle is significantly smaller than in the sulfur analogues (89.2(2)-94.33(11) vs. $\left.92.99(8)-96.84(9)^{\circ}\right)$ and the angle around the bridging carbon atom in the backbone is also smaller (119.5(2)-120.2 $(3)^{\circ}$ vs. 123.54(14)-124.1(2) $)^{\circ}$.

The aluminium species show a correlation between two important structural features: the narrower the $\mathrm{N}-\mathrm{M}-\mathrm{N}$ angle, the greater the metal distance from the $\mathrm{C}_{3} \mathrm{~N}_{2}$ plane and also the greater the folding angle of the heteroaromatic residues. However, in the case of the gallium complexes this tendency is the other way round. Because of these observations there are reasons to believe that the ligand derived from $\mathbf{1}$ coordinates

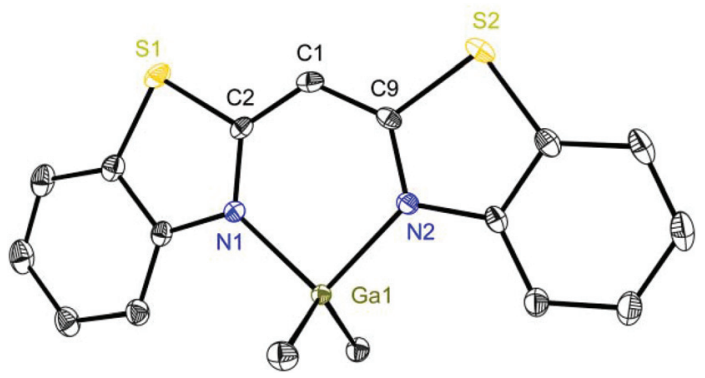

Fig. 6 Molecular structure of $\left[\mathrm{Me}_{2} \mathrm{Ga}\left\{\left(\mathrm{NCSC}_{6} \mathrm{H}_{4}\right)_{2} \mathrm{CH}\right\}\right]$ (8). Anisotropic displacement parameters are depicted at the $50 \%$ probability level. Hydrogen atoms are omitted for clarity. Structural data are given in Tables 1 and 2. more properly gallium than aluminium and the ligand derived from 2 vice versa.

By comparing the structural values of the parent ligands with those of the metallated species given in Table 2 , it can be considered that there is a change in hybridisation of the central bridging carbon atom upon metallation from $\mathrm{sp}^{3}$ to $\mathrm{sp}^{2}$. As an evidence for this statement the angular sum around the bridging carbon atom can be taken into account ranging from $359.9(2)$ to $360.1(2)^{\circ}$, which displays a nearly ideal trigonal planar coordination geometry for $\mathrm{C} 1$ as expected for a $\mathrm{sp}^{2}$-hybridised carbon atom. In both cases the benzothiazole as well as the benzoxazole containing ligand, a shortening of the $\mathrm{C}_{\text {ipso }}-\mathrm{C}_{\text {bridge }}$ bond (starting from 1.5106(15) and 1.4891(15) $\AA$ to approx. $1.39 \AA$ ) and a widening of the $\mathrm{C}_{\text {ipso }}-\mathrm{C}_{\text {bridge }}-\mathrm{C}_{\text {ipso }}$ angle (from $109.59(14)$ and $111.23(9)^{\circ}$ to approx. $120^{\circ}$ ) were observed. Including the corresponding elongated $\mathrm{N}-\mathrm{C}_{\text {ipso }}$ distances in the deprotonated species 3-8, an efficient delocalisation of the lone pair is anticipated. As shown in Scheme 4 there are different mesomeric resonance structures which can be proposed: (a) a carbanionic, (b) an amidic and (c) a completely delocalised canonical form.

Regarding the abovementioned structural changes, species (a) has a certain eligibility as in previous studies within $\left[\mathrm{MeZnCH}\left(2-\mathrm{NC}_{5} \mathrm{H}_{4}\right)_{2}\right]_{2}$ the central deprotonated methanide carbon atom is coordinated by the electropositive zinc atom. ${ }^{4}$ Nevertheless case (c) seems to explain the bonding situation best within the compounds $\mathbf{3 - 8}$, because the $\mathrm{C}-\mathrm{C}$ and $\mathrm{C}-\mathrm{N}$ bond lengths lie in between a distinct single and double bond character $\left(\mathrm{C}\left(\mathrm{sp}^{2}\right)-\mathrm{C}\left(\mathrm{sp}^{3}\right): 1.510 \AA, \mathrm{C}\left(\mathrm{sp}^{2}\right)=\mathrm{C}\left(\mathrm{sp}^{2}\right): 1.335 \AA\right.$, $\left.\mathrm{C}\left(\mathrm{sp}^{2}\right)-\mathrm{N}\left(\mathrm{sp}^{3}\right): 1.43 \AA, \mathrm{C}\left(\mathrm{sp}^{2}\right)=\mathrm{N}\left(\mathrm{sp}^{2}\right): 1.29 \AA\right) .{ }^{34}$ Measurements of ${ }^{1} \mathrm{H},{ }^{15} \mathrm{~N}$-HMBC-NMR data gave evidence that complexes 3, 4, 7 and 8 show the same structure in solution at room temperature (at the NMR time scale) and in the solid state. The coordination geometry concerning the nacnac-like chelating ability can be proven by the apparent cross peaks, which clearly display ${ }^{3} J$-coupling between the protons of the $\mathrm{AlMe}_{2}$ or $\mathrm{GaMe}_{2}$ unit and the nitrogen donor atoms, exemplarily shown in Fig. 5 for compound 7.

Conspicuously within the series from the $\mathrm{AlMe}_{2}$ derivatives via AlMeCl towards $\mathrm{GaMe}_{2}$ the $\mathrm{N}-\mathrm{M}$ distance and the $\mathrm{N}-\mathrm{M}-\mathrm{N}$ angle alter as expected. In comparison with $\mathbf{3}$ and $\mathbf{4}$ the $\mathrm{N}-\mathrm{M}$ distance decreases in 5 and $\mathbf{6}$ because of the more electronegative, electron withdrawing chloro substituent in the latter cases. Concomitantly the $\mathrm{N}-\mathrm{M}-\mathrm{N}$ angles widen.

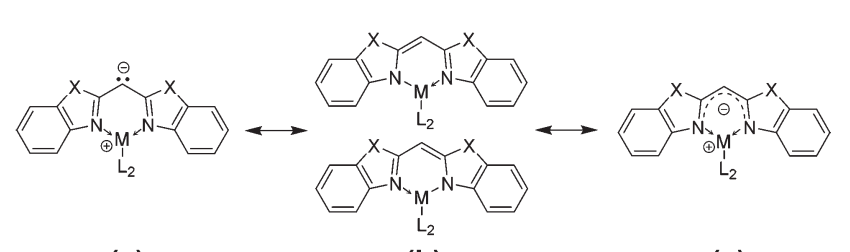

(a)

(b)

(c)

Scheme 4 Mesomeric resonance structures of the bisheterocyclomethanides. 


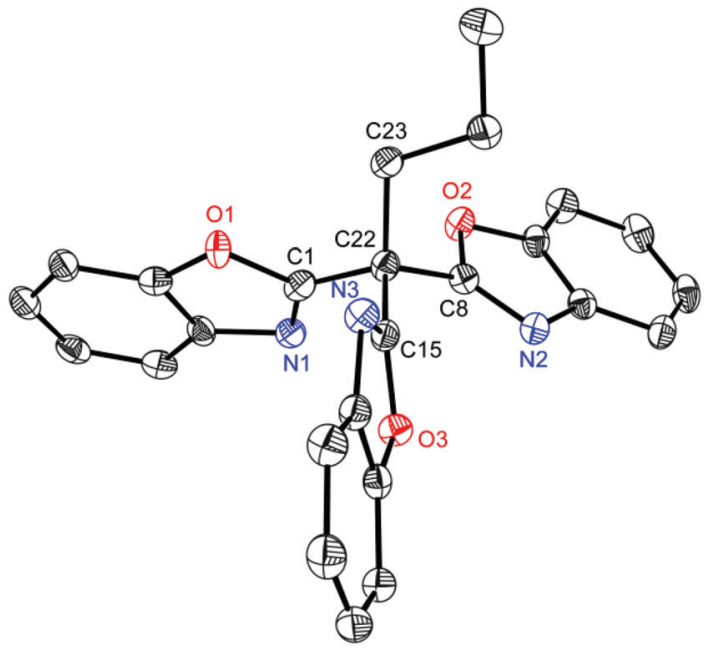

Fig. 7 Molecular structure of $\left(\mathrm{NCOC}_{6} \mathrm{H}_{4}\right)_{3} \mathrm{C}\left(\mathrm{C}_{3} \mathrm{H}_{7}\right)$ (9). Anisotropic displacement parameters are depicted at the $50 \%$ probability level. Hydrogen atoms and the positional disorder are omitted for clarity. Selected bond lengths and angles C22-C1(av) 151.1(10) pm, C22-C8 150.51(16) pm, C22C15 151.20(16) pm, C22-C23 155.04(17) pm; C1-C22-C8(av) 110.0(8) , C1-C22-C15(av) $105.3(14)^{\circ}, \quad \mathrm{C} 1-\mathrm{C} 22-\mathrm{C} 23\left(\right.$ av) $109.9(9)^{\circ}, \mathrm{C} 8-\mathrm{C} 22-\mathrm{C} 15$ $113.07(10)^{\circ}, \mathrm{C} 8-\mathrm{C} 22-\mathrm{C} 23108.69(10)^{\circ}, \mathrm{C} 15-\mathrm{C} 22-\mathrm{C} 23109.91(10)^{\circ}$.

Furthermore, the dimethylgallium compounds 7 and 8 feature increasing $\mathrm{N}-\mathrm{M}$ bond lengths and smaller bite angles due to the bigger covalent radius of the coordinated gallium cation (Al: $1.21 \AA$, Ga: $1.22 \AA$ ). ${ }^{35}$

In addition to the above discussed structures 1-8 the interesting side product $\mathbf{9}$ could be isolated from the synthesis of $\mathbf{1}$ in moderate yields (29\%) and structurally and spectroscopically characterised. In a first attempt to synthesise 1 two equivalents of 2-chlorobenzoxazole were attempted to be lithiated in the 2-position and subsequently coupled via addition of one equivalent of diethylcarbonate. Surprisingly the coupling product 9 shown in Fig. 7 was obtained. It represents a side product of the used $n \mathrm{BuLi}$ with 2-chlorobenzoxazole, where the butyl carbanion is formally substituted three times by a benzoxazole heterocycle.

Compound 9 crystallizes in the monoclinic space group $C 2 / c$ and the central carbon atom C22 shows a nearly ideal tetrahedral coordination environment (105.3(14)-113.07(10) ${ }^{\circ}$. The involved $\mathrm{C}-\mathrm{C}$ bond lengths outgoing from $\mathrm{C} 22$ to the benzoxazole moieties lie in a narrow range from 1.5051(16) to $1.5120(16) \AA$, whereas the $\mathrm{C} 22-\mathrm{C} 23$ distance is significantly longer $(1.5504(17) \AA)$. This shortening is expected for an average $\mathrm{C}\left(\mathrm{sp}^{3}\right)-\mathrm{C}\left(\mathrm{sp}^{3}\right)(1.544 \AA)$ to an average $\mathrm{C}\left(\mathrm{sp}^{3}\right)-\mathrm{C}\left(\mathrm{sp}^{2}\right)$ $(1.510 \AA) .{ }^{34}$

This kind of tripodal, tridentate ligand features interesting coordination abilities because of the presence of soft as well as hard donor atoms within the scaffold and can be regarded as an analogue of trispyrazolylmethanes or even more of trisoxazoline ligands. The latter ones are known to be valuable auxiliary ligands in asymmetric catalysis.
Furthermore, 9 shows structural similarities to the class of scorpionates, which are also tridentate ligands and form facial coordination geometries upon building metal complexes. ${ }^{36}$ As common popular examples the monoanionic trispyrazolylborates and the neutral isoelectronic trispyrazolylmethanes ${ }^{37}$ have to be mentioned, which are used in bioinorganic chemistry to mimic the active sites in metallo proteins in model complexes. $^{38}$

\section{Conclusion}

In summary, a variety of group 13 metal complexes containing bisheterocyclomethanides as ligand systems could successfully be synthesised and structurally evaluated. In each case the metal cation is coordinated in a distorted tetrahedral fashion by the ring-nitrogen atoms acting as Lewis-bases and the ligand became almost perfectly planar. Depending on the considered combination of the heterocycle (benzoxazole or benzothiazole) and the chelated metal (Al or $\mathrm{Ga}$ ) some significant correlations between the folding angle of the scaffold and the metal distance from the $\mathrm{C}_{3} \mathrm{~N}_{2}$ plane were observed. The metal coordination in all cases takes place exclusively by donation of nitrogen atoms within the heterocyclic moieties. The chalcogenes did not participate in coordination neither in the solid state nor in solution as proven in the appropriate crystal structures and the ${ }^{1} \mathrm{H},{ }^{15} \mathrm{~N}$-HMBC-NMR experiments.

These empirical results gave rise to the occurrence of preferred ligand-metal pairs in presumably the most stable complexes: whereas 1 seems to suit gallium more properly, 2 fits aluminium the most.

Moreover, the negative charge arising upon deprotonation seems to be delocalised about the whole ligand backbone as is indicated by the observed $\mathrm{N}-\mathrm{C}_{i p s o}$ and $\mathrm{C}_{i p s o}-\mathrm{C}_{\text {bridge }}$ bond lengths. In this context the carbanionic canonical formula can be neglected, because the linking carbon atoms show clear $\mathrm{sp}^{2}$-hybridisation and no involvement in metal coordination.

Referring to the title of this work one can conclude that bisheterocyclomethanides as new ligand systems can definitely compete with the popular $\beta$-diketiminate ligand and offer promising opportunities for investigating and exploring a new interesting research area.

\section{Experimental section}

\section{General procedures}

All manipulations were carried out under an atmosphere of $\mathrm{N}_{2}$ or Ar by Schlenk techniques. All solvents used within metallation reactions were distilled from $\mathrm{Na}$ or $\mathrm{K}$ before use. The starting materials were purchased commercially and used as received. Ethylbisimidate dihydrochloride was prepared according to a literature method. ${ }^{33}{ }^{1} \mathrm{H},{ }^{13} \mathrm{C},{ }^{15} \mathrm{~N}$ and ${ }^{27} \mathrm{Al} \mathrm{NMR}$ spectroscopic data were recorded on a Bruker Avance $500 \mathrm{MHz}$, a Bruker Avance $400 \mathrm{MHz}$ and a Bruker Avance $300 \mathrm{MHz}$ spectrometer and referenced to the deuterated solvent ( $\left.t h f-\mathrm{d}_{8}\right)$. 
Elemental analyses (C, H, N and S) were carried out on a Vario EL3 at the Mikroanalytisches Labor, Institut für Anorganische Chemie, University of Göttingen. All EI-MS spectra $(70 \mathrm{eV})$ were recorded on a Finnigan MAT 95.

\section{Ligand syntheses}

Both ligand systems were synthesised by cyclocondensation reaction of a suitable linker derived from malonic acid and the corresponding ortho-substituted anilines.

$\left(\mathbf{N C O C}_{6} \mathbf{H}_{4}\right)_{2} \mathbf{C H}_{2}$ (1). 2-Aminophenol (1.99 g, $18.0 \mathrm{mmol}$, 2.0 eq.) and ethylbisimidate dihydrochloride $(2.11 \mathrm{~g}, 9.1 \mathrm{mmol}$, 1.0 eq.) were dissolved in methanol $(50 \mathrm{~mL})$. Then the reaction mixture was heated to reflux for $3 \mathrm{~h}$ and, after cooling to rt, stored at $-32{ }^{\circ} \mathrm{C}$ in a fridge. The resulting crystalline material was filtered off, washed subsequently with sat. aq. $\mathrm{NaHCO}_{3}$ solution $(2 \times 50 \mathrm{~mL})$ and water $(2 \times 50 \mathrm{~mL})$ and dried under reduced pressure. Crystals suitable for X-ray diffraction experiments could be obtained upon recrystallisation from ethanol. Pale yellow crystals were obtained in a yield of $1.29 \mathrm{~g}$ (5.1 mmol, 56\%). Anal. Calcd for $\mathrm{C}_{15} \mathrm{H}_{10} \mathrm{~N}_{2} \mathrm{O}_{2}\left(250.25 \mathrm{~g} \mathrm{~mol}^{-1}\right)$ : C, 71.99; H, 4.03; N, 11.19. Found: C, 71.86; H, 4.03; N, 11.12; $\delta^{1} \mathrm{H}\left(300 \mathrm{MHz}\right.$, thf- $\left.\mathrm{d}_{8}\right): 7.70-7.62(\mathrm{~m}, 2 \mathrm{H}, \mathrm{H} 5), 7.59-7.50$ (m, $2 \mathrm{H}, \mathrm{H} 8), 7.37-7.27$ (m, $4 \mathrm{H}, \mathrm{H} 6+\mathrm{H} 7), 4.70$ (s, $2 \mathrm{H}, \mathrm{H} 10)$; $\delta^{13} \mathrm{C}\left\{{ }^{1} \mathrm{H}\right\}\left(75 \mathrm{MHz}\right.$, thf-d $\mathrm{d}_{8}$ ): 161.46 (s, $\left.2 \mathrm{C}, \mathrm{C} 2\right), 152.35$ (s, $2 \mathrm{C}$, C9), 142.66 (s, 2 C, C4), 125.89 (s, 2 C, C7), 125.17 (s, 2 C, C6), 120.83 (s, 2 C, C5), 111.30 (s, 2 C, C8), 29.58 (s, 1 C, C10); $\delta^{15} \mathrm{~N}\left\{{ }^{1} \mathrm{H}\right\} \quad(30 \mathrm{MHz}$, thf-d $)$ ): -133.56 (s); EI-MS, $\mathrm{m} / \mathrm{z}$ (\%): 250 (100) $[\mathrm{M}]^{+}, 132(25)\left[\mathrm{M}-\mathrm{NCOC}_{6} \mathrm{H}_{4}\right]^{+}$.

$\left(\mathbf{N C S C}_{6} \mathbf{H}_{4}\right)_{2} \mathbf{C H}_{2}$ (2). 2-Aminothiophenol (10.0 g, $80.0 \mathrm{mmol}$, 2.0 eq.) and malononitrile (2.64 g, $40.0 \mathrm{mmol}, 1.0$ eq.) were dissolved in ethanol $(40 \mathrm{~mL})$. Then the reaction mixture was heated to reflux for $6 \mathrm{~h}$ and, after cooling to rt, stored at $-32{ }^{\circ} \mathrm{C}$ in a fridge. The resulting yellow precipitate was filtered off, washed with hexane $(2 \times 50 \mathrm{~mL})$ and dried under reduced pressure. Crystals suitable for X-ray diffraction experiments could be obtained upon recrystallisation from ethanol. A yellow powder was obtained in a yield of $8.36 \mathrm{~g}$ (30.0 mmol, 74\%). Anal. Calcd for $\mathrm{C}_{15} \mathrm{H}_{10} \mathrm{~N}_{2} \mathrm{~S}_{2}$ (282.37 $\mathrm{g} \mathrm{mol}^{-1}$ ): C, 63.80; H, 3.57; $\mathrm{N}, 9.92 ; \mathrm{S}, 22.71$. Found: C, 63.80; H, 3.52; N, 9.90; S, 22.63; $\delta^{1} \mathrm{H}\left(300 \mathrm{MHz}\right.$, thf- $\left.\mathrm{d}_{8}\right): 7.97$ (ddd, $J_{\mathrm{HH}}=8.2,1.2,0.6 \mathrm{~Hz}, 2 \mathrm{H}$, H5), 7.92 (ddd, $J_{\mathrm{HH}}=7.9,1.3,0.6 \mathrm{~Hz}, 2 \mathrm{H}, \mathrm{H} 8$ ), 7.45 (ddd, $\left.J_{\mathrm{HH}}=7.9,7.3,1.3 \mathrm{~Hz}, 2 \mathrm{H}, \mathrm{H} 6\right), 7.36$ (ddd, $J_{\mathrm{HH}}=8.1,7.3$, $1.3 \mathrm{~Hz}, 2 \mathrm{H}, \mathrm{H} 7), 4.97$ (s, $2 \mathrm{H}, \mathrm{H} 10) ; \delta^{13} \mathrm{C}\left\{{ }^{1} \mathrm{H}\right\}$ (75 MHz, thf-d ${ }_{8}$ ): 166.68 (s, 2 C, C2), 154.47 (s, 2 C, C4), 137.04 (s, 2 C, C9), 126.79 (s, 2 C, C6), 125.94 (s, 2 C, C7), 123.88 (s, 2 C, C5), 122.49 (s, 2 C, C8), 39.19 (s, 1 C, C10); $\delta^{15} \mathrm{~N}\left\{{ }^{1} \mathrm{H}\right\}$ (30 MHz, thf-d $\mathrm{d}_{8}$ ): -65.02 (s); EI-MS, $m / z(\%): 282$ (100) $[\mathrm{M}]^{+}, 148$ (10) $\left[\mathrm{M}-\mathrm{NCSC}_{6} \mathrm{H}_{4}\right]^{+}$.

\section{Metallation reactions}

To a solution of the corresponding ligand 1 or 2 (1.0 eq.) in toluene a slight excess of the pure organometallic reactant $\mathrm{AlMe}_{3}, \mathrm{AlMe}_{2} \mathrm{Cl}$ or $\mathrm{GaMe}_{3}$ (1.1 eq.) was slowly added at $0{ }^{\circ} \mathrm{C}$. The reaction mixture was stirred overnight and allowed to warm to rt. In the case of $\mathbf{5}$ and $\mathbf{6}$ the resulting precipitate was filtered off, and the reaction mixture of $\mathbf{3}$ and $\mathbf{4}$ afforded a clear solution. Afterwards the volume of the solution was reduced to a few milliliters and the resulting concentrated solution was stored at $-32{ }^{\circ} \mathrm{C}$ in a fridge. Overnight crystals suitable for X-ray diffraction experiments could be obtained. The crystals thus formed were filtered, washed twice with precooled toluene or hexane $\left(0^{\circ} \mathrm{C}\right)$ and finally dried in a vacuum. The given yields below are just based on the received crystals unless stated otherwise. No further improvement of the yields was applied to the remaining solutions because of impurities upon repeated precipitation.

$\left[\mathbf{M e}_{2} \mathbf{A l}\left\{\left(\mathbf{N C O C}_{6} \mathbf{H}_{4}\right)_{2} \mathbf{C H}\right\}\right]$ (3). Colourless crystals were obtained in a yield of $46 \mathrm{mg}$ ( $0.15 \mathrm{mmol}, 8 \%$; not optimised). Anal. Calcd for $\mathrm{C}_{17} \mathrm{H}_{15} \mathrm{AlN}_{2} \mathrm{O}_{2}\left(306.29 \mathrm{~g} \mathrm{~mol}^{-1}\right)$ : C, 66.66; H, 4.94; $\mathrm{N}$, 9.15. Found: C, 66.65; H, 5.08; N, 9.19; $\delta^{1} \mathrm{H}(300 \mathrm{MHz}$, thf-d 8 ): 7.42 (ddd, $J_{\mathrm{HH}}=7.8,1.2,0.6 \mathrm{~Hz}, 4 \mathrm{H}, \mathrm{H} 5+\mathrm{H} 8$ ), $7.29\left(\mathrm{td}, J_{\mathrm{HH}}=7.7,1.2 \mathrm{~Hz}, 2 \mathrm{H}, \mathrm{H} 6\right), 7.19\left(\mathrm{dd}, J_{\mathrm{HH}}=7.7,1.4 \mathrm{~Hz}\right.$, $2 \mathrm{H}, \mathrm{H} 7), 5.41$ (s, $1 \mathrm{H}, \mathrm{H} 10),-0.48$ (s, $6 \mathrm{H}, \mathrm{H} 11) ; \delta^{13} \mathrm{C}\left\{{ }^{1} \mathrm{H}\right\}$ (75 MHz, thf-d 8 ): 169.42 (s, 2 C, C2), 149.39 (s, 2 C, C9), 137.31 (s, 2 C, C4), 125.81 (s, 2 C, C6), 123.86 (s, 2 C, C7), 113.58 (s, 2 C, C5), 110.67 (s, 2 C, C8), 60.48 (s, 1 C, C10), -10.22 (s, $2 \mathrm{C}, \mathrm{C} 11) ; \delta^{15} \mathrm{~N}\left\{{ }^{1} \mathrm{H}\right\}\left(30 \mathrm{MHz}\right.$, thf-d $\left.\mathrm{d}_{8}\right):-231.31$ (s); $\delta^{27} \mathrm{Al}\left\{{ }^{1} \mathrm{H}\right\}$ (78 MHz, thf-d $\mathrm{d}_{8}$ ): 155.08 (s); EI-MS, $m / z$ (\%): 306 (9) $[\mathrm{M}]^{+}$, $291(100)[\mathrm{M}-\mathrm{Me}]^{+}, 276(10)[\mathrm{M}-2 \mathrm{Me}]^{+}, 145.5$ (10) $[\mathrm{M}-\mathrm{Me}]^{2+}$.

$\left[\mathbf{M e}_{2} \mathbf{A l}\left\{\left(\mathbf{N C S C}_{6} \mathbf{H}_{4}\right)_{2} \mathbf{C H}\right\}\right]$ (4). Orange crystals were obtained in a yield of $450 \mathrm{mg}$ (1.3 mmol, 7\%, not optimised). Anal. Calcd for $\mathrm{C}_{17} \mathrm{H}_{15} \mathrm{AlN}_{2} \mathrm{~S}_{2}$ (338.41 $\left.\mathrm{g} \mathrm{mol}^{-1}\right)$ : C, 60.33; H, 4.47; $\mathrm{N}, 8.28$; S, 18.95. Found: C, 60.66; H, 4.52; N, 8.26; S, 18.72; $\delta^{1} \mathrm{H}(500 \mathrm{MHz}$, thf-d 8$): 7.68$ (ddd, $J_{\mathrm{HH}}=7.9,1.2,0.5 \mathrm{~Hz}, 2 \mathrm{H}$, H8), 7.59 (ddd, $J_{\mathrm{HH}}=8.2,1.0,0.6 \mathrm{~Hz}, 2 \mathrm{H}, \mathrm{H} 5$ ), 7.39 (ddd, $\left.J_{\mathrm{HH}}=8.2,7.4,1.3 \mathrm{~Hz}, 2 \mathrm{H}, \mathrm{H} 6\right), 7.20\left(\mathrm{ddd}, J_{\mathrm{HH}}=7.9,7.4,1.0 \mathrm{~Hz}\right.$, $2 \mathrm{H}, \mathrm{H} 7), 6.05$ (s, $1 \mathrm{H}, \mathrm{H} 10),-0.43$ (s, $6 \mathrm{H}, \mathrm{H} 11) ; \delta^{13} \mathrm{C}\left\{{ }^{1} \mathrm{H}\right\}$ (125 MHz, thf $-\mathrm{d}_{8}$ ): 167.22 (s, $\left.2 \mathrm{C}, \mathrm{C} 2\right), 149.25$ (s, $\left.2 \mathrm{C}, \mathrm{C} 4\right)$, 129.48 (s, 2 C, C9), 127.52 (s, 2 C, C6), 124.01 (s, 2 C, C7), 122.56 (s, 2 C, C8), 116.09 (s, 2 C, C5), 82.56 (s, 1 C, C10), -9.54 (s, 2 C, C11); $\delta^{15} \mathrm{~N}\left\{{ }^{1} \mathrm{H}\right\}$ (30 MHz, thf-d $\mathrm{d}_{8}$ ): -201.16 (s); $\delta^{27} \mathrm{Al}\left\{{ }^{1} \mathrm{H}\right\}(130 \mathrm{MHz}$, thf-d $): 151.02$ (s); EI-MS, $m / z$ (\%): 338 (11) $[\mathrm{M}]^{+}, 323$ (100) $[\mathrm{M}-\mathrm{Me}]^{+}, 308$ (5) $[\mathrm{M}-2 \mathrm{Me}]^{+}, 161.5$ (14) $[\mathrm{M}-\mathrm{Me}]^{2+}$.

[ClMeAl $\left.\left\{\left(\mathrm{NCOC}_{6} \mathbf{H}_{4}\right)_{2} \mathbf{C H}\right\}\right]$ (5). A colourless powder was obtained in a yield of $1.21 \mathrm{~g}$ (3.7 mmol, 74\%). Anal. Calcd for $\mathrm{C}_{16} \mathrm{H}_{12} \mathrm{AlClN}_{2} \mathrm{O}_{2}$ (326.72 $\left.\mathrm{g} \mathrm{mol}^{-1}\right)$ : C, 58.82; H, 3.70; N, 8.57. Found: $\mathrm{C}, 60.13 ; \mathrm{H}, 4.04 ; \mathrm{N}, 8.25$ (deviation due to remaining toluene); $\delta^{1} \mathrm{H}\left(500 \mathrm{MHz}\right.$, thf-d $\left.\mathrm{d}_{8}\right): 7.51$ (dddd, $J_{\mathrm{HH}}=17.1,8.0$, 1.1, 0.6 Hz, $4 \mathrm{H}, \mathrm{H} 5+\mathrm{H} 8$ ), 7.35 (dd, $\left.J_{\mathrm{HH}}=7.7,1.2 \mathrm{~Hz}, 2 \mathrm{H}, \mathrm{H} 6\right)$, 7.28-7.24 (m, 2 H, H7), 5.62 (s, 1 H, H10), -0.18 (s, 3 H, H11); $\delta^{13} \mathrm{C}\left\{{ }^{1} \mathrm{H}\right\}\left(125 \mathrm{MHz}\right.$, thf-d $\left.\mathrm{d}_{8}\right): 169.31$ (s, $\left.2 \mathrm{C}, \mathrm{C} 2\right), 149.22$ (s, $2 \mathrm{C}$, C9), 136.57 (s, 2 C, C4), 126.12 (s, 2 C, C6), 124.60 (s, 2 C, C7), 114.08 (s, 2 C, C5), 110.98 (s, 2 C, C8), 61.79 (s, 1 C, C10), -10.18 (s, $1 \mathrm{C}, \mathrm{C} 11) ; \delta^{15} \mathrm{~N}\left\{{ }^{1} \mathrm{H}\right\} \quad\left(50 \mathrm{MHz}\right.$, thf-d $\left.\mathrm{d}_{8}\right):-231.52$ (s); $\delta^{27} \mathrm{Al}\left\{{ }^{1} \mathrm{H}\right\}$ (78 MHz, thf-d s) 133.35 (s); EI-MS, m/z (\%): 326 (26) [M] $]^{+}, 311$ (100) $[\mathrm{M}-\mathrm{Me}]^{+}, 291(4)[\mathrm{M}-\mathrm{Cl}]^{+}, 155.5(10)[\mathrm{M}-\mathrm{Me}]^{2+}$.

$\left[\mathrm{ClMeAl}\left\{\left(\mathrm{NCSC}_{6} \mathbf{H}_{4}\right)_{2} \mathbf{C H}\right\}\right](6)$. A yellow powder was obtained in a yield of $3.33 \mathrm{~g}(9.3 \mathrm{mmol}, 93 \%)$. Anal. Calcd for $\mathrm{C}_{16} \mathrm{H}_{12} \mathrm{AlClN}_{2} \mathrm{~S}_{2}$ (358.84 $\left.\mathrm{g} \mathrm{mol}^{-1}\right): \mathrm{C}, 53.56 ; \mathrm{H}, 3.37 ; \mathrm{N}, 7.81$; $\mathrm{S}$, 17.87. Found: C, 53.09; H, 3.32; N, 7.92; S, 17.40; $\delta^{1} \mathrm{H}\left(500 \mathrm{MHz}\right.$, thf-d $\left.\mathrm{d}_{8}\right): 7.77$ (ddd, $J_{\mathrm{HH}}=8.2,1.0,0.6 \mathrm{~Hz}, 2 \mathrm{H}, \mathrm{H} 8$ ), $7.72\left(\mathrm{ddd}, J_{\mathrm{HH}}=7.9,1.2,0.6 \mathrm{~Hz}, 2 \mathrm{H}, \mathrm{H} 5\right), 7.47-7.40$ 
(m, $2 \mathrm{H}, \mathrm{H} 6$ ), 7.26 (ddd, $J_{\mathrm{HH}}=7.9,7.4,1.0 \mathrm{~Hz}, 2 \mathrm{H}, \mathrm{H} 7$ ), 6.26 (s, $1 \mathrm{H}, \mathrm{H} 10),-0.18$ (s, $3 \mathrm{H}, \mathrm{H} 11) ; \delta^{13} \mathrm{C}\left\{{ }^{1} \mathrm{H}\right\}$ (125 MHz, thf-d $\mathrm{d}_{8}$ ): 167.55 (s, 2 C, C2), 148.29 (s, 2 C, C4), 129.12 (s, 2 C, C9), 127.80 (s, 2 C, C6), 124.68 (s, 2 C, C7), 122.75 (s, 2 C, C8), 116.69 (s, 2 C, C5), 83.55 (s, 1 C, C10), -9.27 (s, 1 C, C11); $\delta^{15} \mathrm{~N}\left\{{ }^{1} \mathrm{H}\right\} \quad\left(50 \mathrm{MHz}\right.$, thf-d $\left.{ }_{8}\right):-204.41(\mathrm{~s}) ; \delta^{27} \mathrm{Al}\left\{{ }^{1} \mathrm{H}\right\} \quad(78 \mathrm{MHz}$, thf-d ${ }_{8}$ ): 128.26 (s); EI-MS, m/z (\%): 358 (28) [M] $]^{+}, 343$ (100) $[\mathrm{M}-\mathrm{Me}]^{+}, 323(4)[\mathrm{M}-\mathrm{Cl}]^{+}, 171.5(18)[\mathrm{M}-\mathrm{Me}]^{2+}$.

$\left[\mathbf{M e}_{2} \mathbf{G a}\left\{\left(\mathrm{NCOC}_{6} \mathbf{H}_{4}\right)_{2} \mathbf{C H}\right\}\right]$ (7). Pale yellow crystals were obtained in a yield of $0.583 \mathrm{~g}(1.54 \mathrm{mmol}, 31 \%$, not optimised). Anal. Calcd for $\mathrm{C}_{17} \mathrm{H}_{15} \mathrm{GaN}_{2} \mathrm{O}_{2}\left(349.04 \mathrm{~g} \mathrm{~mol}{ }^{-1}\right)$ : C, 58.50; H, 4.33; N, 8.03. Found: C, 58.45; H, 4.35; N, 8.21; $\delta^{1} \mathrm{H}(500 \mathrm{MHz}$, thf-d 8$): 7.38$ (ddd, $J_{\mathrm{HH}}=8.0,1.1,0.6 \mathrm{~Hz}, 2 \mathrm{H}$, H8), 7.29-7.21 (m, $4 \mathrm{H}, \mathrm{H} 5+\mathrm{H} 6), 7.14$ (ddd, $J_{\mathrm{HH}}=8.0,7.2$, $1.5 \mathrm{~Hz}, 2 \mathrm{H}, \mathrm{H} 7), 5.25$ (s, $1 \mathrm{H}, \mathrm{H} 10),-0.06$ (s, $6 \mathrm{H}, \mathrm{H} 11)$; $\delta^{13} \mathrm{C}\left\{{ }^{1} \mathrm{H}\right\}\left(75 \mathrm{MHz}\right.$, thf-d $_{8}$ ): 168.63 (s, $\left.2 \mathrm{C}, \mathrm{C} 2\right), 149.35$ (s, $2 \mathrm{C}$, C9), 138.41 (s, 2 C, C4), 125.53 (s, 2 C, C6), 123.21 (s, 2 C, C7), 112.95 (s, 2 C, C5), 110.40 (s, 2 C, C8), 59.23 (s, 1 C, C10), -7.39 (s, 2 C, C11); $\delta^{15} \mathrm{~N}\left\{{ }^{1} \mathrm{H}\right\}(50 \mathrm{MHz}$, thf-d 8 ): -229.86 (s); EI-MS, $m / z$ (\%): 348 (11) $[\mathrm{M}]^{+}, 333$ (100) $[\mathrm{M}-\mathrm{Me}]^{+}, 318$ (17) $[\mathrm{M}-2 \mathrm{Me}]^{+}, 166.5(10)[\mathrm{M}-\mathrm{Me}]^{2+}, 69(11) \mathrm{Ga}^{+}$.

$\left[\mathbf{M e}_{2} \mathbf{G a}\left\{\left(\mathbf{N C S C}_{6} \mathbf{H}_{4}\right)_{2} \mathbf{C H}\right\}\right]$ (8). Yellow crystals were obtained in a yield of $138 \mathrm{mg}$ (0.36 mmol, 36\%, not optimised). Anal. Calcd for $\mathrm{C}_{17} \mathrm{H}_{15} \mathrm{GaN}_{2} \mathrm{~S}_{2}\left(381.16 \mathrm{~g} \mathrm{~mol}^{-1}\right)$ : C, 53.57; H, 3.97; $\mathrm{N}, 7.35 ; \mathrm{S}, 16.82$. Found: C, 53.75; H, 3.94; N, 7.43; S, 16.74; $\delta^{1} \mathrm{H}(500 \mathrm{MHz}$, thf-d 8$): 7.64$ (ddd, $J_{\mathrm{HH}}=7.8,1.2,0.6 \mathrm{~Hz}, 2 \mathrm{H}$, H8), 7.40 (ddd, $J_{\mathrm{HH}}=8.1,1.1,0.6 \mathrm{~Hz}, 2 \mathrm{H}, \mathrm{H} 5$ ), 7.36-7.32 (m, $2 \mathrm{H}, \mathrm{H6}$ ), 7.14 (ddd, $\left.J_{\mathrm{HH}}=7.9,7.3,1.2 \mathrm{~Hz}, 2 \mathrm{H}, \mathrm{H} 7\right), 5.87$ (s, $1 \mathrm{H}, \mathrm{H} 10),-0.02$ (s, $6 \mathrm{H}, \mathrm{H} 11) ; \delta^{13} \mathrm{C}\left\{{ }^{1} \mathrm{H}\right\}(75 \mathrm{MHz}$, thf-d 8 ): 165.82 (s, 2 C, C2), 149.77 (s, 2 C, C4), 129.57 (s, 2 C, C9), 127.35 (s, 2 C, C6), 123.48 (s, 2 C, C7), 122.40 (s, 2 C, C8), 115.44 (s, 2 C, C5), 81.28 (s, 1 C, C10), -6.71 (s, 2 C, C11); $\delta^{15} \mathrm{~N}\left\{{ }^{1} \mathrm{H}\right\}\left(50 \mathrm{MHz}\right.$, thf-d $\left.\mathrm{d}_{8}\right):-199.22$ (s); EI-MS, $m / z$ (\%): 380 (13) $[\mathrm{M}]^{+}, 365$ (100) $[\mathrm{M}-\mathrm{Me}]^{+}, 350$ (21) $[\mathrm{M}-2 \mathrm{Me}]^{+}, 182.5$ (9) $[\mathrm{M}-\mathrm{Me}]^{2+}, 69(14) \mathrm{Ga}^{+}$.

$\left(\mathrm{NCOC}_{6} \mathrm{H}_{4}\right)_{3} \mathrm{C}\left(\mathrm{C}_{3} \mathrm{H}_{7}\right)$ (9). At $-78^{\circ} \mathrm{C}$ to a solution of 2-chlorobenzoxazol (5.0 g, $3.8 \mathrm{~mL}, 32.6 \mathrm{mmol}, 1.0$ eq.) in thf (25 mL) a solution of $n \mathrm{BuLi}(2.15 \mathrm{~m}$ in hexane, $15.2 \mathrm{~mL}, 32.6 \mathrm{mmol}, 1.0$ eq.) was slowly added and stirred overnight. After warming at rt the remaining $n \mathrm{BuLi}$ was hydrolysed by addition of water $(120 \mathrm{~mL})$ and the reaction mixture was extracted with DCM $(6 \times 50 \mathrm{~mL})$. The combined organic layers were dried over $\mathrm{MgSO}_{4}$ and the solvent was evaporated under reduced pressure. After recrystallisation from acetone, light brown crystals were obtained in a yield of $1.30 \mathrm{~g}$ (3.2 mmol, 29\% based on 2-chlorobenzoxazole). Anal. Calcd for $\mathrm{C}_{25} \mathrm{H}_{19} \mathrm{~N}_{3} \mathrm{O}_{3}\left(409.4 \mathrm{~g} \mathrm{~mol}^{-1}\right)$ : C, 73.34; H, 4.68; N, 10.26. Found: C, 72.60; H, 4.55; N, 10.20. $\delta^{1} \mathrm{H}\left(500 \mathrm{MHz}\right.$, thf- $\left.\mathrm{d}_{8}\right): 7.75-7.68(\mathrm{~m}, 3 \mathrm{H}, \mathrm{H} 5), 7.63-7.54(\mathrm{~m}$, $3 \mathrm{H}, \mathrm{H} 8), 7.42-7.31$ (m, $6 \mathrm{H}, \mathrm{H} 6+\mathrm{H} 7), 3.11-3.01$ (m, $2 \mathrm{H}, \mathrm{H} 11)$, 1.71-1.60 (m, $2 \mathrm{H}, \mathrm{H} 12), 1.03\left(\mathrm{t},{ }^{3} J_{\mathrm{HH}}=7.3 \mathrm{~Hz}, 3 \mathrm{H}, \mathrm{H} 13\right) ; \delta^{13} \mathrm{C}\left\{{ }^{1} \mathrm{H}\right\}$ (125 MHz, thf-d $)$ ): 163.18 (s, 3 C, C2), 152.25 (s, 3 C, C9), 141.92 (s, 3 C, C4), 126.56 (s, 3 C, C6), 125.49 (s, 3 C, C7), 121.35 (s, 3 C, C5), 111.77 (s, 3 C, C8), 51.83 (s, 1 C, C10), 39.96 (s, 1 C, C11), 19.34 (s, $1 \mathrm{C}, \mathrm{C} 12), 14.57$ (s, $1 \mathrm{C}, \mathrm{C} 13) ; \delta^{15} \mathrm{~N}\left\{{ }^{1} \mathrm{H}\right\}\left(50 \mathrm{MHz}\right.$, thf-d $\left.\mathrm{d}_{8}\right):-128.85$ (s); EI-MS, $m / z(\%): 409$ (7) $[\mathrm{M}]^{+}, 380(28)[\mathrm{M}-\mathrm{Et}]^{+}, 367$ (100) $[\mathrm{M}-$ $\mathrm{Pr}]^{+}, 263(7)\left[\mathrm{M}-\mathrm{NCOC}_{6} \mathrm{H}_{4}-\mathrm{Et}\right]^{+}$.

\section{X-ray crystallographic studies}

Single crystals were selected from a Schlenk flask under an argon or nitrogen atmosphere and covered with perfluorated polyether oil on a microscope slide, which was cooled with a nitrogen gas flow using the X-TEMP2 device. ${ }^{39}$ An appropriate crystal was selected using a polarized microscope, mounted on the tip of a MiTeGen ${ }^{\odot}$ MicroMount or glass fiber, fixed to a goniometer head and shock cooled by the crystal cooling device.

The data for 1-9 were collected from shock-cooled crystals at $100(2) \mathrm{K}$. The data of $\mathbf{1 , 2}, \mathbf{5}, \mathbf{6 , 8}$ and $\mathbf{9}$ were collected on an Incoatec Mo Microsource ${ }^{40}$ and compound 7 was collected on an Incoatec Ag Microsource each equipped with mirror optics and an APEX II detector with a D8 goniometer. The data of 3 and 4 were measured on a Bruker TXS-Mo rotating anode with mirror optics and an APEX II detector with a D8 goniometer. All diffractometers were equipped with a low-temperature device and used either $\mathrm{MoK}_{\alpha}$ radiation of $\lambda=71.073 \mathrm{pm}$ or $\mathrm{AgK}_{\alpha}$ radiation of $\lambda=56.086 \mathrm{pm}$. The data were integrated with saint $^{41}$ and an empirical absorption correction (Sadabs) ${ }^{42}$ was applied. The structures were solved by direct methods (Shelxs97) and refined by full-matrix least-squares methods against $F^{2}$ (Shelxl-97). ${ }^{34,43}$ All non-hydrogen atoms were refined with anisotropic displacement parameters. The hydrogen atoms were refined isotropically on calculated positions using a riding model with their $U_{\text {iso }}$ values constrained to equal 1.5 times the $U_{\text {eq }}$ of their pivot atoms for terminal $\mathrm{sp}^{3}$ carbon atoms and 1.2 times for all other carbon atoms. Disordered moieties were refined using bond length restraints and isotropic displacement parameter restraints.

Crystallographic data for the structures reported in this paper have been deposited with the Cambridge Crystallographic Data Centre. The CCDC numbers, crystal data and experimental details for the X-ray measurements are listed in the ESI. +

\section{Acknowledgements}

Thanks to the Danish National Research Foundation DNRF funded Center for Materials Crystallography (CMC) for partial support and the Land Niedersachsen for providing a fellowship in the GAUSS PhD program.

The authors thank Prof. Dr. Dr. h.c. mult. H. W. Roesky for the numerous subject-specific discussions and Dr. Regine Herbst-Irmer for the support in crystallographic issues.

\section{Notes and references}

1 W. W. Schoeller, Inorg. Chem., 2011, 50, 2629-2633.

2 For review: F. Baier, Z. Fei, H. Gornitzka, A. Murso, S. Neufeld, M. Pfeiffer, I. Rüdenauer, A. Steiner, T. Stey and D. Stalke, J. Organomet. Chem., 2002, 661, 111-127.

3 H. Gornitzka and D. Stalke, Angew. Chem., Int. Ed. Engl, 1994, 33, 693-695. 
4 H. Gornitzka, C. Hemmert, G. Bertrand, M. Pfeiffer and D. Stalke, Organometallics, 2000, 19, 112-114.

5 For review: L. Mahalakshmi and D. Stalke, Struct. Bonding, 2002, 103, 85-113.

6 H. Gornitzka and D. Stalke, Organometallics, 1994, 13, 4398-4405.

7 M. Pfeiffer, F. Baier, T. Stey, D. Leusser, D. Stalke, B. Engels, D. Moigno and W. Kiefer, J. Mol. Model., 2000, 6, 299-311.

8 M. Pfeiffer, A. Murso, L. Mahalakshmi, D. Moigno, W. Kiefer and D. Stalke, Eur. J. Inorg. Chem., 2002, 3222-3234.

9 A. Steiner and D. Stalke, J. Chem. Soc., Chem. Commun., 1993, 444-446.

10 A. Steiner and D. Stalke, Angew. Chem., 1995, 107, 1908-1910.

11 H. Gornitzka and D. Stalke, Eur. J. Inorg. Chem., 1998, 311-317.

12 A. Steiner and D. Stalke, Organometallics, 1995, 14, 2422-2429.

13 M. Stender, B. E. Eichler, N. J. Hardman, P. P. Power, J. Prust, M. Noltemeyer and H. W. Roesky, Inorg. Chem., 2001, 40, 2794-2799.

14 B. Qian, D. L. Ward and M. R. Smith III, Organometallics, 1998, 17, 3070-3076.

15 S. Singh, H.-J. Ahn, A. Stasch, V. Jancik, H. W. Roesky, A. Pal, M. Biadene, R. Herbst-Irmer, M. Noltemeyer and H.-G. Schmidt, Inorg. Chem., 2006, 45, 1853-1860.

16 Z. Yang, H. Zhu, X. Ma, J. Chai, H. W. Roesky, C. He, J. Magull, H.-G. Schmidt and M. Noltemeyer, Inorg. Chem., 2006, 45, 1823-1827.

17 S. Nagendran and H. W. Roesky, Organometallics, 2008, 27, 457-492.

18 Y. Ding, H. W. Roesky, M. Noltemeyer, H.-G. Schmidt and P. P. Power, Organometallics, 2001, 20, 1190-1194.

19 A. Jana, H. W. Roesky, C. Schulzke, A. Döring, T. Beck, A. Pal and R. Herbst-Irmer, Inorg. Chem., 2009, 48, 193-197.

20 Z. Yang, H. Zhu, X. Ma, J. Chai, H. W. Roesky, C. He, J. Magull, H.-G. Schmidt and M. Noltemeyer, Inorg. Chem., 2006, 45, 1823-1827.

21 Y. Cheng, D. J. Doyle, P. B. Hitchcock and M. F. Lappert, Dalton Trans., 2006, 4449-4460.

22 N. Kuhn, J. Fahl, S. Fuchs, M. Steimann, G. Henkel and A. H. Maulitz, Z. Anorg. Allg. Chem., 1999, 625, 2108-2114.

23 N. Kuhn, S. Fuchs and M. Steimann, Eur. J. Inorg. Chem., 2001, 359-361.
24 N. Kuhn, S. Fuchs and M. Steimann, Z. Anorg. Allg. Chem., 2002, 628, 458-462.

25 C. E. Radzewich, I. A. Guzei and R. F. Jordan, J. Am. Chem. Soc., 1999, 121, 8673-8674.

26 C. Cui, H. W. Roesky, H.-G. Schmidt, M. Noltemeyer, H. Hao and F. Cimpoesu, Angew. Chem., Int. Ed., 2000, 112, 4444-4446.

27 X. Li, X. Cheng, H. Song and C. Cui, Organometallics, 2007, 26, 1039-1043.

28 N. J. Hardman, B. E. Eichler and P. P. Power, Chem. Commun., 2000, 1991-1992.

29 M. Asay, C. Jones and M. Driess, Chem. Rev., 2011, 111, 354-396.

30 Y. Mizuhata, T. Sasamori and N. Tokitoh, Chem. Rev., 2009, 109, 3479-3511.

31 D. Li, Y. Peng, C. Geng, K. Liu and D. Kong, Dalton Trans., 2013, 42, 11295-11303.

32 B. D. Ward and L. H. Gade, Chem. Commun., 2012, 48, 10587-10599.

33 H. B. Ammar, J. Le Nôtre, M. Salem, M. T. Kaddachi and P. H. Dixneuf, J. Organomet. Chem., 2002, 662, 63-69.

34 P. Müller, R. Herbst-Irmer, A. L. Spek, T. R. Schneider and M. R. Sawaya, in Crystal Structure Refinement - A Crystallographer's Guide to SHELXL, ed. P. Müller, IUCr Texts on Crystallography, Oxford University Press, Oxford, UK, 2006, vol. 8.

35 Cambridge Structural Database, taken from "CSD Elemental Radii”, http://www.ccdc.cam.ac.uk/Lists/ResourceFileList/Elemental_Radii.xlsx, last modified: 21st June 2012.

36 S. Trofimenko, Chem. Rev., 1993, 93, 943-980.

37 D. L. Reger, Comments Inorg. Chem., 1997, 21, 1-28.

$38 \mathrm{~W}$. Kaim and B. Schwederski, Bioanorganische Chemie Zur Funktion chemischer Elemente in Lebensprozessen, B. G. Teubner Verlag, Wiesbaden, 2005.

39 (a) T. Kottke and D. Stalke, J. Appl. Crystallogr., 1993, 26, 615-619; (b) T. Kottke, R. J. Lagow and D. Stalke, J. Appl. Crystallogr., 1996, 29, 465-468; (c) D. Stalke, Chem. Soc. Rev., 1998, 27, 171-178.

40 T. Schulz, K. Meindl, D. Leusser, D. Stern, J. Graf, C. Michaelsen, M. Ruf, G. M. Sheldrick and D. Stalke, J. Appl. Crystallogr., 2009, 42, 885-891.

41 SAINT v7.68A in Bruker APEX v2011.9, Bruker AXS Inst. Inc., Madison, USA, 2008.

42 G. M. Sheldrick, $S A D A B S$ 2008/2, Universität Göttingen, Germany, 2008.

43 (a) G. M. Sheldrick, Acta Crystallogr., Sect. A: Fundam. Crystallogr., 2008, 64, 112-122; (b) G. M. Sheldrick, Acta Crystallogr., Sect. A: Fundam. Crystallogr., 1990, 46, 467-473. 